\title{
CONTROL TECHNOLOGY AND EXPOSURE ASSESSMENT FOR OCCUPATIONAL EXPOSURE TO BERYLLIUM: MICHIGAN SPRING AND STAMPING MUSKEGON, MICHIGAN
}

\author{
PRINCIPAL AUTHORS: \\ Alan S. Echt \\ Keith G. Crouch \\ Robert Kurimo
}

\author{
REPORT DATE: \\ February 5, 2004
}

FILE NO.:

EPHB 263-12a

\section{U.S. DEPARTMENT OF HEALTH AND HUMAN SERVICES \\ Centers for Disease Control and Prevention \\ National Institute for Occupational Safety and Health Division of Applied Research and Technology 4676 Columbia Parkway, R5 \\ Cincinnati, Ohio 45226}




\section{INTRODUCTION}

The National Institute for Occupational Safety and Health (NIOSH), working under an interagency agreement with the Office of Regulatory Analysis of the Occupational Safety and Health Administration (OSHA), is conducting a study to survey occupational exposures to beryllium and to document engineering controls and work practices affecting those exposures. The performance of a thorough industrial hygiene survey for a variety of individual employers provides valuable and useful information to the public and employers in the industries included in the work. The principal objectives of this study are:

1. To identify and describe the control technology and work practices in use in operations associated with occupational exposures to beryllium, as well to determine additional controls, work practices, substitute materials, or technology that can further reduce occupational beryllium exposures.

2. To measure full-shift, personal breathing zone, particulate exposures to beryllium. These samples provide examples of exposures to beryllium among workers across the many industries where beryllium is encountered. These exposure data, along with the control data described above, provide a picture of the conditions in the selected industries.

This site visit was conducted on August 21 and 22, 2003 by NIOSH researchers from the Engineering and Physical Hazards Branch, Division of Applied Research and Technology, in Cincinnati, Ohio.

Occupational exposure to berylliurn occurs at places where the chemical is mined, processed, or converted into metal, alloys, and other chemicals. Workers engaged in machining metals containing beryllium, recycling beryllium from scrap alloys, or using beryllium products may also be exposed to higher levels of beryllium. The number of workers exposed to beryllium or beryllium compounds has been estimated to be 21,000 (ATSDR 2002). There is a need to understand the nature of these beryllium exposures, what is causing the exposures, and what steps are being taken or could be taken to reduce the exposures (e.g., engineering controls, work practices, and personal protective equipment).

The OSHA general industry standard sets a permissible exposure limit (PEL) at 2 micrograms of beryllium per cubic meter of air $\left(\mu \mathrm{g} / \mathrm{m}^{3}\right)$ for an 8-hour time-weighted average (TWA), or $5 \mu \mathrm{g} / \mathrm{m}^{3}$ of beryllium in air, not to exceed 30 minutes at a time (29 CFR 1910.1000). OSHA also requires that employees should never be exposed to more than $25 \mu \mathrm{g} / \mathrm{m}^{3}$ of beryllium in air, regardless of how short the exposure. The current NIOSH Recommended Exposure Limit (REL) for beryllium is $0.5 \mu \mathrm{g} / \mathrm{m}^{3}$, while the current American Conference of Governmental Industrial Hygienists (ACGIH ${ }^{(3)}$ ) Threshold Limit Value (TLV) is an 8-hr TWA of $2 \mu \mathrm{g} / \mathrm{m}^{3}$, and a Short Term Exposure Limit (STEL) of $10 \mu \mathrm{g} / \mathrm{m}^{3}$ (NIOSH 1997, ACGIH 2001).

Surface sampling is not appropriate for estimating exposures but is useful for evaluating process control and cleanliness and for determining suitability for release of equipment. There are no surface contamination regulations applicable to the use of beryllium in general industry. However, a useful guideline is provided by the U.S. Department of Energy (DOE), where DOE and its contractors are required to conduct routine surface sampling to determine housekeeping conditions wherever beryllium is present in operational areas of DOE/NNSA facilities (10 CFR 850). Those facilities must maintain removable surface contamination levels that do not exceed $3 \mu \mathrm{g} / 100 \mathrm{~cm}^{2}$ during non-operational periods (10 CFR 850). The DOE also has release criteria that must be met before beryllium-contaminated equipment or other items can be released to the general public or released for use in a non-beryllium area of a DOE facility. These criteria state that the removable contamination level of equipment or item surfaces does not exceed the higher of $0.2 \mu \mathrm{g} / 100 \mathrm{~cm}^{2}$ or the level of beryllium in the soil in the area of release. Removable contamination is defined as "beryllium contamination that can be removed from surfaces by nondestructive means, such as casual contact, wiping, brushing, or washing" (10 CFR 850). 


\section{METHODS}

This field study was conducted in accordance with 42 CFR $85 a$, the NIOSH regulations governing the investigation of places of employment ( 42 CFR $85 a$ ). The first day at the site was spent meeting with company personnel (company management, employees) to arrange sampling on the subsequent days, and to walk through the plant to begin the industrial hygiene assessment of exposure and control technology. Prior to sampling, the worker selected for sampling was briefed on the sampling procedures to be conducted.

Personal breathing zone and general area particulate samples were collected and analyzed for beryllium. Particulate samples were collected at a flow rate of 2 liters/minute using a calibrated battery-powered sampling pump connected via flexible tubing to a $37-\mathrm{mm}$ diameter, $0.8 \mu \mathrm{m}$ pore-size mixed cellulose ester filter in a 3-piece, clear plastic cassette sealed with a cellulose shrink band (SKC Inc., Eighty Four, PA). Samples were analyzed by inductively coupled plasma spectroscopy (ICP) in accordance with NIOSH Method 7300 modified for hot-block digestion (NIOSH 1994). Each sample was prepared for analysis by transfer to a clean $50 \mathrm{~mL}$ centrifuge tube. A $10 \mathrm{~mL}$ aliquot of $1: 1 \mathrm{v} / \mathrm{v}$ ASTM Type II water:concentrated nitric acid was then added to each sample. The samples were then digested for 40 minutes in a hot-block digester at $110^{\circ} \mathrm{C}$. After cooling, the samples were diluted to $25 \mathrm{~mL}$ with ASTM Type II water, sealed, and shaken. The limit of detection (LOD) for this method is $0.004 \mu \mathrm{g}$ of beryllium per sample. The limit of quantitation (LOQ) is $0.01 \mu \mathrm{g} / \mathrm{sample.} \mathrm{Results} \mathrm{between} \mathrm{the} \mathrm{LOD} \mathrm{and} \mathrm{LOQ} \mathrm{are} \mathrm{semi-quantilative.}$

Surface wipe samples were collected using Ghost Wipe ${ }^{\mathrm{TM}}$ sampling wipes (Environmental Express, Mt. Pleasant, SC) in accordance with ASTM Method D 6966-03, except that the template was held in place, rather than taped in place, to prevent movement during sampling (ASTM 2003). The samples were digested and analyzed according to NIOSH Method 7300 modified for hot-block digestion as described above. The LOD for this method is $0.003 \mu \mathrm{g}$ of beryllium per sample. The LOQ is $0.009 \mu \mathrm{g} / \mathrm{sample}$.

To complement the time-weighted-average area and personal sampling discussed above, near real-time measurements were also taken of the airborne particle concentration and size distribution at and near the stamping machine which was producing an electrical connector made of a $2 \%$ copper-beryllium alloy. The real-time data can help to better define the location and intensity of aerosol emission sources, and correlate variability in emission rates with process conditions, factors of interest in the development of engineering controls. Also, knowledge of aerosol concentration variation at sites occupied by the machine operator can help the operator to minimize exposure by improving work practices. Finally, in the case of beryllium-containing aerosol, there is substantial evidence that the presence of an ultrafine component increases the toxicity for chronic beryllium disease, so knowledge of the aerosol size distribution can help in evaluation of the health hazard.

The primary instrument used for real-time measurements was a Scanning Mobility Particle Sizer (SMPS), (Model 3034, TSI Incorporated, Shoreview, MN). The SMPS classifies airborne particle diameters in the range 10 to 487 nanometers, and concentrations up to $10^{7}$ particles per cubic centimeter. Each scan of a size distribution takes 3 minutes. Some data was also taken with an Electrical Aerosol Detector (EAD), (Model 3070A, TSI Incorporated, St. Paul, MN). The EAD responds to particles in the diameter range of $10 \mathrm{~nm}$ to about 1 micron. It measures the product of aerosol diameter times the concentration, in a range of 0.01 to $2500 \mathrm{~mm} / \mathrm{cm}^{3}$. The measurement is updated on the display once a second.

During the site visit, information pertinent to process operation and control effectiveness (e.g. control methods, ventilation rates, work practices, use of personal protective equipment, etc.) was also collected. A thorough description of the process is essential to understanding the role of engineering controls and work practices. The work practices and use of personal protective equipment were also recorded for the 
worker sampled. Information was obtained from conversations with the worker to determine if the sampling day was a typical work day. This information helped place the sampling results in proper perspective.

The summary of engineering control information includes such items as ventilation flow rates and distance measurements. The proximity of the control systems to open doors or windows, general ventilation intakes and exhausts, and other interacting equipment (i.e., pedestal fans) was also noted. The age and history of the control systems, cost of control installation, maintenance practices, and operation and maintenance costs were determined from facility management, when possible.

$\mathrm{NIOSH}$ researchers calculated the exposures from the analytical results after correcting for the results of field blanks. For the employee sampled, an eight-hour time weighted average (TWA) exposure to beryllium was calculated. The TWA was calculated assuming that no additional beryllium exposure occurred during the unsampled period. For the samples that were below the LOD, an LOD-derived concentration (LOD/ $\sqrt{2}$ ) was used to calculate the TWA (Hornung and Reed 1990).

\section{PROCESS DESCRIPTION AND CONTROL TECHNOLOGY}

On August 20-22, research personnel from NIOSH conducted a site visit at Michigan Spring and Stamping in Muskegon, Michigan. The purpose of the study was to identify and describe the control technology and work practices in use during operations associated with occupational exposures to beryllium, and measure those exposures.

\section{Process Description and Work Practices}

Coiled 0.0150 -in thick (nominal) by 5/16-in wide beryllium-copper strip (Guardian Metal Sales, Inc., Chicago, IL) is fed from a spool into a Finzer-U.S. Baird model no. 200 stamping machine (U.S. Baird Corporation, Stratford, CT) at a rate of 10 feet per minute (Figure 1 shows the spool). The stamping machine cuts, perforates, folds, and ejects the finished part, a clip for a headlight assembly (Figure 2 shows the point of operation of the stamping machine). This is the only beryllium part currently produced at Michigan Spring and Stamping, and this is the only stamping machine used in its production. The parts are ejected using compressed air, and fall into a cardboard box. The operator has suspended a rag across the inside of the box. This rag catches small chips. Scrap falls down a chute to another cardboard box on the floor. The operator dumps the parts into a metal tray. When three trays are full, the operator carries them through the plant to a heat-treating oven, where they are heated at $600{ }^{\circ} \mathrm{F}$ for an hour. After cooling, the parts are dumped into boxes and weighed, packed, and shipped. The weighing operation takes place on a table near the stamping machine. The machine operator is a lead man who is also responsible for four other machine tools. Consequently, he spends only a portion of his day at the Finzer-U.S. Baird stamping machine. He also has a desk in the production area where he completes paperwork and performs data entry tasks on a computer terminal.

\section{Control Technology}

There were no engineering controls associated with this production process. In the winter, tempered air is supplied to the production area through a cloth ventilation duct suspended from the ceiling. In the summer, plant doors and windows are open. There are pedestal fans located in the production area; the one closest to this stamping machine was not running during the survey. 


\section{Air Sampling}

\section{RESULTS}

Personal breathing zone and area air sampling results are summarized in Tables 1 and 2 . The results were all less than the occupational exposure limits for beryllium. The operator's 8-hour time weighted average beryllium exposures were $0.021 \mu \mathrm{g} / \mathrm{m}^{3}$ on August 21 and $0.006 \mu \mathrm{g} / \mathrm{m}^{3}$ on August 22. The shorter sampling time on the second sampling day reflects the fact that production of the product stopped at around 10:30 am after the operator made enough parts to fill the order. Figure 3 illustrates where the area samples were collected around the stamping machine.

The primary question that the SMPS measurements have helped to address is whether or not the stamping process results in airborne, respirable beryllium aerosol. The finished part is ejected from the stamping die using a timed pulse of compressed air that delivers the part into a cloth suspended vertically over a cardboard box. The part is stopped when it hits the cloth, then falls into the box. Aerosol present in the jet of air and in the part collection box was sampled with the SMPS when the stamping machine was running, both when parts were being produced, and when parts were not being produced. Figure 4 shows an example of SMPS measurement of number of particles vs. particle diameter in the part collection box when there were no parts being produced, and with parts in production. The difference is apparently insignificant, and may be attributable to variations in ambient background aerosol concentration and to variations in the number of particles in the ejector air jet. Differences between SMPS measurements taken in the trimmings collection box and in the ambient air were indiscernible.

Measurements of aerosol concentration taken with the EAD in ambient air, in the parts collection box, and in the trimmings collection box were consistent with the above-mentioned results taken with the SMPS.

\section{Wipe Sampling}

Wipe sampling results are presented in Table 3. These results ranged from less than the limit of detection on a table in the break room to $11 \mu \mathrm{g} / 100 \mathrm{~cm}^{2}$ on the cover of the scrap chute on the stamping machine. After collecting a wipe sample on the floor in front of the stamping machine, the NIOSH researchers repeatedly cleaned that area using laboratory wipes and distilled water. Sampling after cleaning showed that this procedure reduced beryllium contamination from $3 \mu \mathrm{g} / 100 \mathrm{~cm}^{2}$ to $0.2 \mu \mathrm{g} / 100$ $\mathrm{cm}^{2}$. When the same area was wipe-sampled approximately 24 hours later, the amount of beryllium on the surface had risen to $1.5 \mu \mathrm{g} / 100 \mathrm{~cm}^{2}$. Collecting a wipe sample reduced the surface contamination on the cover of the scrap chute from $11 \mu \mathrm{g} / 100 \mathrm{~cm}^{2}$ to $2.2 \mu \mathrm{g} / 100 \mathrm{~cm}^{2}$ the next day. These results suggest that clean-up of surface beryllium contamination on this machine should be a relatively straightforward process.

\section{CONCLUSIONS AND RECOMMENDATIONS}

Air sampling results were all less than the most stringent occupational exposure limit for airborne beryllium, the NIOSH REL of $0.5 \mu \mathrm{g} / \mathrm{m}^{3}$. The operator's TWA exposures, $0.021 \mu \mathrm{g} / \mathrm{m}^{3}$ on day 1 , and 0.006 $\mu \mathrm{g} / \mathrm{m}^{3}$ on day 2 , were well below the applicable exposure standards.

Surface monitoring is used to monitor the effectiveness of routine housekeeping and spill clean up efforts in a workplace and to help diagnose the sources of beryllium contamination. Monitoring surface contamination levels is an indispensable tool for ensuring that beryllium emissions from operations are under control. The results at this facility indicate that surface beryllium contamination on some parts of 
the stamping machine exceed the DOE guidelines (which do not apply to this plant) of $3 \mu \mathrm{g} / 100 \mathrm{~cm}^{2}$ for production areas during non-operational periods. The DOE guidelines also establish $0.2 \mu \mathrm{g} / 100 \mathrm{~cm}^{2}$ for non-beryllium production areas, which was exceeded at the weighing station. The following recommendations are based on the DOE guidelines:

Limit access to the beryllium stamping machine, so that other non-beryllium workers will not track through, or be exposed to, settled dust produced by the machine. A sticky-mat can be placed at the entrance to the beryllium-processing area, to reduce tracking of settled dust into other parts of the plant by the machine operator. If the floor surrounding the stamping machine is currently porous, either move the machine or apply a non-porous coating to the floor. Keep this floor free of oil and grease, to permit the HEPA vacuum to effectively remove beryllium dust from it. Other surfaces that collect beryllium dust (on the machine, for example) should also be kept free of grease and oil, if possible. When moving beryllium parts from the limited access area near the machine, make sure that the parts and the containers holding the parts are free of beryllium dust (less than $0.2 \mu \mathrm{g} / 100 \mathrm{~cm}^{2}$ ), to avoid contaminating other locations in the plant (the weighing station or annealing oven, for example).

Other guidelines for housekeeping in workplaces that use beryllium are available from several sources. In 1999, OSHA issued a Hazard Information Bulletin, Preventing Adverse Health Effects from Exposure to Beryllium on the Job (OSHA 1999). The following housekeeping steps were among the recommendations in that document.

Employers should ensure that employees use the following safe practices to reduce their exposure to beryllium:

- use high-efficiency particulate air (HEPA) vacuums to clean equipment and the floor around their work areas;

- do not leave a film of dust on the floor after the water dries if a wet mop is used to clean;

- do not use long vacuum hoses and do not loop the hoses that are used;

- never use compressed air to clean parts or working surfaces;

- avoid prolonged skin contact with beryllium particulate; and

- do not allow workers to eat, drink, smoke, or apply cosmetics at their work stations. 


\section{References}

10 CFR 850 [2003]. Department of Energy: chronic beryllium disease prevention program.

29 CFR 1910.1000 [2001]. Occupational Safety and Health Administration: air contaminants.

42 CFR 85a [2002]. Public Health Service, HHS: occupational safety and health investigations of places of employment.

ACGIH [2001]. Threshold limit values for chemical substances. Cincinnati, OH: American Conference of Governmental Industrial Hygienists.

ASTM [2003]. Standard practice for collection of settled dust samples using wipe sampling methods for subsequent determination of metals. West Conshohocken, PA: American Society for Testing and Materials International, Designation D 6966-03.

ATSDR [2002]. Toxicological profile for beryllium. Atlanta, GA: U.S. Department of Health and Human Services, Public Health Service, Agency for Toxic Substances and Disease Registry.

Hornung R, Reed L [1990]. Estimation of average concentration in the presence of nondetectable values. Applied Occupational and Environmental Hygiene, 5(1):46-51.

NIOSH [1994]. NIOSH manual of analytical methods. 4th rev. ed., Eller PM, ed. Cincinnati, OH: U.S. Department of Health and Human Services, Public Health Service, Centers for Disease Control and Prevention, National Institute for Occupational Safety and Health, DHHS (NIOSH) Publication No. 94-113.

NIOSH [1997]. NIOSH pocket guide to chemical hazards. Cincinnati, OH: U.S. Department of Health and Human Services, Public Health Service, Centers for Disease Control and Prevention, National Institute for Occupational Safety and Health, DHHS (NIOSH) Publication No. 97-140.

OSHA [1999]. OSHA Hazard Information Bulletins: Preventing Adverse Health Effects from Exposure to Beryllium on the Job. Hazard Information Bulletin no. 19990902 
Table 1 - Operator Personal Breathing Zone Beryllium Sampling Results Michigan Spring and Stamping, August 21 and 22, 2003

\begin{tabular}{|c|c|c|c|c|c|c|}
\hline & $\begin{array}{c}\text { Beryllium } \\
(\mu \mathrm{g} / \text { sample })\end{array}$ & $\begin{array}{c}\text { Average } \\
\text { Flow } \\
(\mathrm{L} / \mathrm{min})\end{array}$ & $\begin{array}{c}\text { Pump } \\
\text { Sample } \\
\text { Time (min) }\end{array}$ & $\begin{array}{c}\text { Sample } \\
\text { Volume } \\
(\mathrm{L})\end{array}$ & $\begin{array}{c}\text { Concentration } \\
\mu \mathrm{g} / \mathrm{m}^{3}\end{array}$ & $\begin{array}{c}8-\mathrm{hr} \text { TWA } \\
\mu \mathrm{g} / \mathrm{m}^{3}\end{array}$ \\
\hline August 21 & 0.02 & 2 & $450^{*}$ & 899 & 0.022 & 0.021 \\
\hline August 22 & $(0.006)$ & 2 & 231 & 460 & 0.013 & 0.006 \\
\hline
\end{tabular}

*Pump fault 11:04@264 min, noted \& restarted 11:50, off at 2:55@186 min

Numbers in parentheses indicates a semi-quantitative value between the limit of detection of $0.004 \mu \mathrm{g}$ of beryllium per sample and the limit of quantitation of $0.01 \mu \mathrm{g}$ of beryllium per sample.

Table 2 - Beryllium Area Sample Results

Michigan Spring and Stamping, August 21 and 22, 2003

\begin{tabular}{|c|c|c|c|c|c|c|}
\hline Location & $\begin{array}{l}\text { Beryllium } \\
(\mu \mathrm{g} / \mathrm{sample})\end{array}$ & $\begin{array}{c}\text { Average } \\
\text { Flow } \\
\text { (L/min) }\end{array}$ & $\begin{array}{c}\text { Pump } \\
\text { Sample } \\
\text { Time } \\
\text { (min) }\end{array}$ & $\begin{array}{c}\text { Sample } \\
\text { Volume } \\
\text { (L) }\end{array}$ & $\begin{array}{l}\text { Concentration } \\
\left(\mu \mathrm{g} / \mathrm{m}^{3}\right)\end{array}$ & $\begin{array}{c}\text { 8-hr } \\
\text { TWA } \\
\left(\mu \mathrm{g} / \mathrm{m}^{3}\right)\end{array}$ \\
\hline \multicolumn{7}{|c|}{ August 21} \\
\hline Atop stamping machine & 0.025 & $2^{*}$ & 500 & 1002 & 0.025 & 0.026 \\
\hline Outdoors on fenceline & $N D^{* *}$ & 2 & 240 & 486 & 0.006 & 0.003 \\
\hline On vertislide machine & $(0.005)$ & 2 & 498 & 1006 & 0.005 & 0.005 \\
\hline On electrical cabinet & ND & 2 & 499 & 1006 & 0.003 & 0.003 \\
\hline Suspended from air hose & ND & 2 & 496 & 1006 & 0.003 & 0.003 \\
\hline $\begin{array}{l}\text { Inside of box, in front of air } \\
\text { ejector }\end{array}$ & 0.054 & 2 & 309 & 626 & 0.086 & 0.056 \\
\hline \multicolumn{7}{|c|}{ August 22} \\
\hline $\begin{array}{l}\text { On machine cover, } \\
\text { operator's left }\end{array}$ & 0.011 & 2 & 235 & 466 & 0.024 & 0.012 \\
\hline $\begin{array}{l}\text { On top of stamping } \\
\text { machine, above ejector }\end{array}$ & 0.022 & 2 & 230 & 458 & 0.048 & 0.023 \\
\hline $\begin{array}{l}\text { Inside of box, in front of air } \\
\text { ejector }\end{array}$ & 0.055 & 2 & 229 & 454 & 0.121 & 0.058 \\
\hline $\begin{array}{l}\text { On machine cover, } \\
\text { operator's right }\end{array}$ & ND & 2 & 233 & 459 & 0.006 & 0.003 \\
\hline
\end{tabular}

*Pump flows were rounded to one digit.

*ND indicates a result less than the limit of detection, $0.004 \mu \mathrm{g}$ of beryllium per sample. Airborne concentrations reported in those rows are estimates based on $\mathrm{LOD} / \sqrt{2}$.

Numbers in parentheses indicate a semi-quantitative value between the limit of detection of $0.004 \mu \mathrm{g}$ of beryllium per sample and the limit of quantitation of $0.01 \mu \mathrm{g}$ of beryllium per sample. 
Table 3 - Beryllium Wipe Sample Results

Michigan Spring and Stamping, August 21 and 22, 2003

\begin{tabular}{|l|l|l|}
\hline $\begin{array}{l}\text { NIOSH Field } \\
\text { ID }\end{array}$ & Location & $\begin{array}{l}\text { Beryllium } \\
\left(\mu \mathrm{g} / 100 \mathrm{~cm}^{2}\right)\end{array}$ \\
\hline W-1 & Operator's panel & 1.2 \\
\hline W-2 & Floor at operator position (uncleaned) & 3 \\
\hline W-3 & Floor at operator position after cleaning & 0.2 \\
\hline W-4 & Cover of scrap chute on stamping machine & 11 \\
\hline W-5 & Front of stamping machine, on top of dies & 6.7 \\
\hline W-6 & Back panel of stamping machine, not panel with nameplate & 0.15 \\
\hline W-7 & $\begin{array}{l}\text { Side of clear plastic machine cover, outside surface, vertical, on } \\
\text { operator's left }\end{array}$ & 0.46 \\
\hline W-8 & Touch pad of microwave oven used occasionally by operator & 0.038 \\
\hline W-9 & Front of operator's tool box drawers & 1.3 \\
\hline W-10 & Maintenance and safety administrator's desk, in front of PC & $\mathrm{ND}$ \\
\hline W-11 & Break room, center of table closest to AquaFina vending machine & $\mathrm{ND}$ \\
\hline W-14 & Wipe of table where parts are weighed, small chip visible in sample & 0.35 \\
\hline W-15 & Wipe of table where parts are weighed, no chip visible in sample & 0.082 \\
\hline W-16 & Operator's work table, many small chips visible in sample & 0.017 \\
\hline W-17 & Machine control panel, same as W- 1, one day later & 1.7 \\
\hline W-18 & Same location as W-2 and W-3, one day later & 1.5 \\
\hline W-19 & Same location as W-4, one day later & 2.2 \\
\hline
\end{tabular}

Samples $W-12$ and $W-13$ were field blanks. The average value of these blanks was subtracted from those of the field samples to obtain the corrected results.

ND indicates a result less than the limit of detection for this method of $0.003 \mu \mathrm{g}$ of beryllium per sample. Results in parentheses indicate a semi-quantitative value between the limit of detection of $0.003 \mu \mathrm{g}$ of beryllium per sample and the limit of quantitation of $0.009 \mu \mathrm{g}$ of beryllium per sample. 


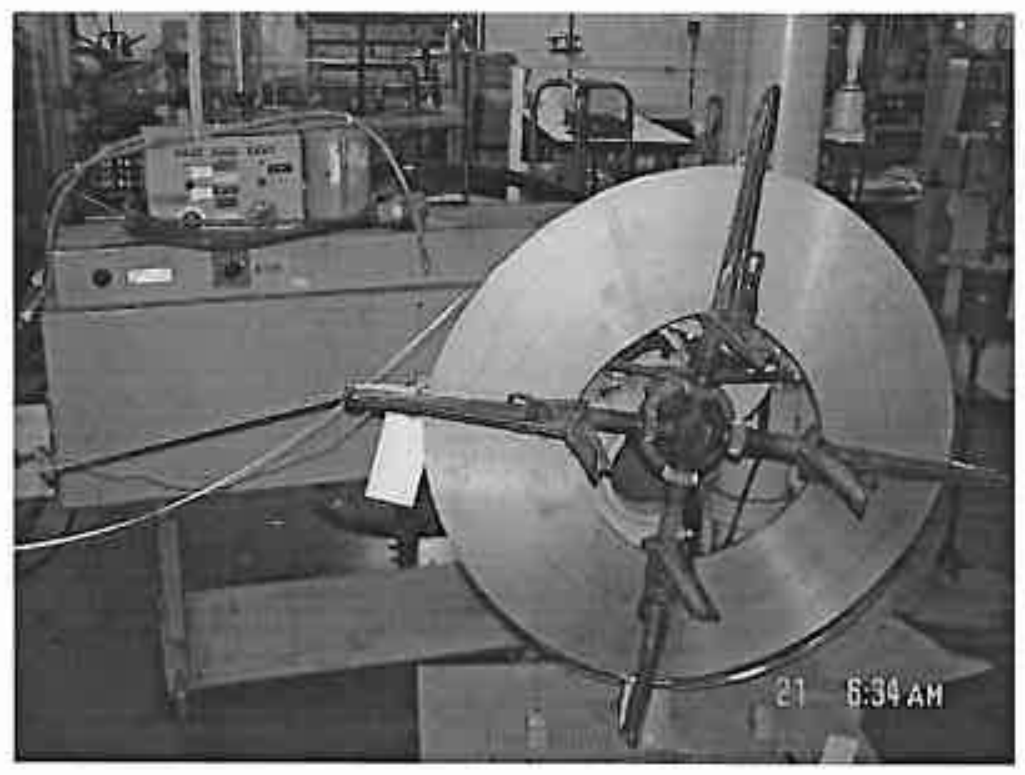

Figure 1: Beryllium-copper alloy strip mounted on spool.

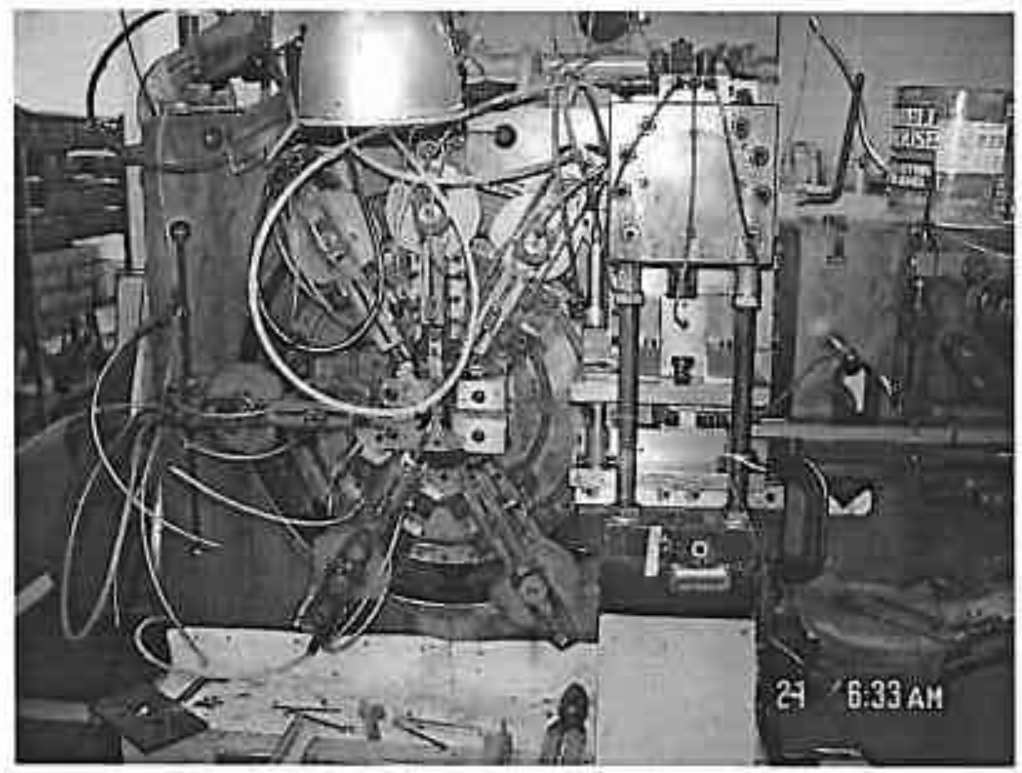

Figure 2: Point of operation of stamping machine. 


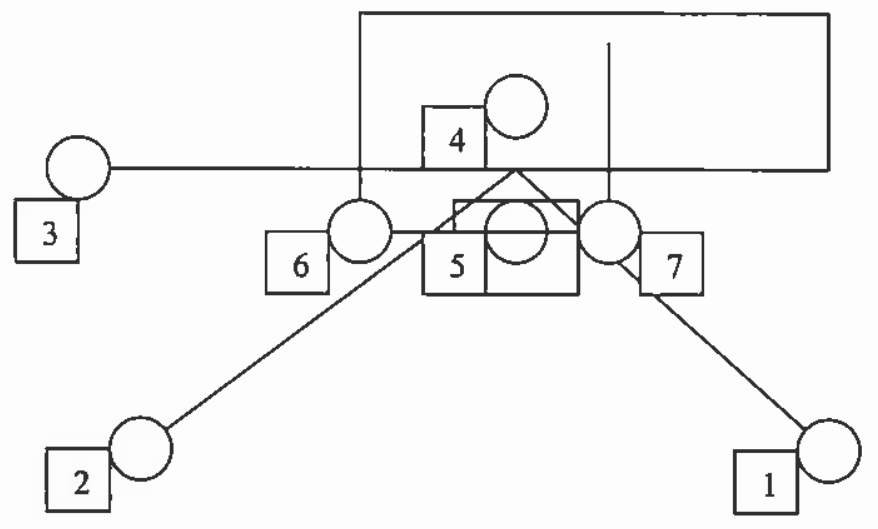

Figure 3: Location of area samples (not to scale)

1. Suspended from air hose, $5 \mathrm{ft}, 6$ in high, $5 \mathrm{ft} 6$ in from stamping dies

2. On Verti-Slide machine, $5 \mathrm{ft}, 6$ in high, $5 \mathrm{ft}$ from stamping dies

3. On electrical cabinet, $5 \mathrm{ft}, 3$ in high, $4 \mathrm{ft}$ from stamping dies

4. On top of Finzer-Baird stamping machine, $5 \mathrm{ft}, 5$ in high

5. Inside of box in front of air-ejector.

6. On corner of plastic machine cover (raised), $5 \mathrm{ft}, 9$ inches high

7. On corner of plastic machine cover (raised), $5 \mathrm{ft}, 9$ inches high 
Figure 4. SMPS Data

Michlgan Spring \& Stamplng, August 21, 2003

In Parts Collectlon Box, with and without parts In production

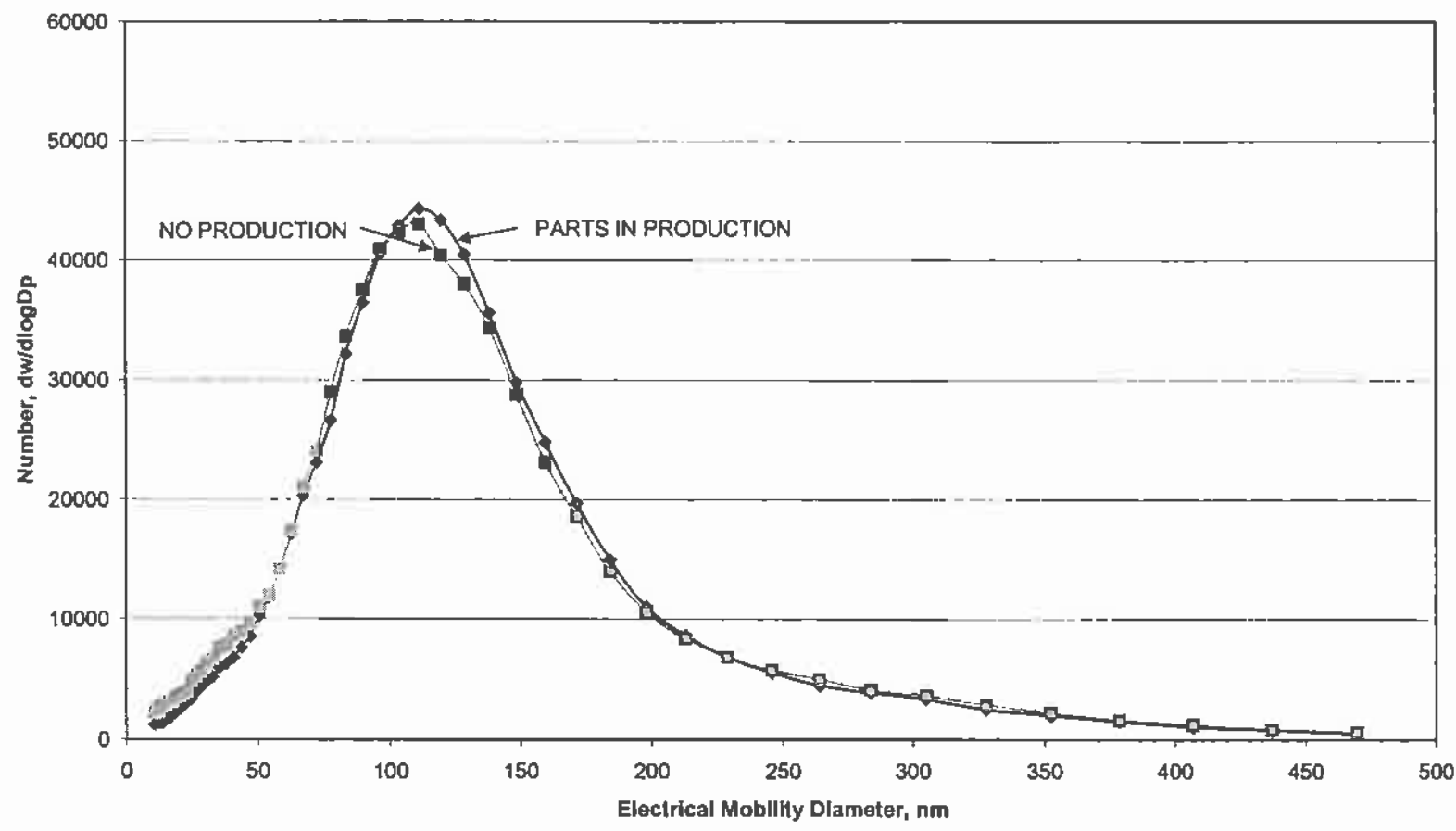

